so that in addition to inducing tolerance before grafting we are faced with the problem of maintaining tolerance in the long term. It may be that the continued presence of donor lymphoid cells, intermingled with those of the host, is necessary for tolerance to be permanent. It is this, no doubt, which prompts the considerable attention which is directed to the part played by lymphoid tissue chimerism in the maintenance of the tolerant state. Unfortunately, no firm conclusions can be reported. As a whole, these Proceedings are now rathor more specialized than previously, and contain less material of interest to the general immunologist, but they remain the best assemblage of advances in transplantation research.

\section{Food Preservation}

THE report of the C.S.I.R.O. Division of Food Preservation for the years 1962-64 records work carried out under the following headings: physics, food chemistry, plant physiology, microbiology, meat research, fish, fresh fruit and vegetables, frozen fruit and vegetables, dried foods, canning, packaging and irradiation (Pp. vi +77 . Sydney: Commonwealth Scientific and Industrial Research Organization, 1964). Microbiological work has included investigations on the relation between chemical composition and spore resistance. The heat resistance of spores from the eighteen organisms studied varied by a factor of more than 700 ; the principal metal constituent in nearly all species was calcium. The calcium content increased significantly with heat resistance while the magnesium content decreased. Diamino pimelic acid also increased with heat resistance and, on a spore unit basis, this acid and dipicolinic acid hexosamine were highly correlated among themselves and with calcium content and spore weight. Studies on responses of meat-spoilage organisms to changes in environment showed that species of Pseudomonas, the main spoilage organisms on fresh meat stored in air, are inhibited in certain other atmospheres. Investigations to apply this to carcass preservation are being continued. Meat research was devoted largely to various aspects of meat quality and to a study of the complex biochemical events occurring in postmortem muscle. Meat from emaciated animals, in addition to having a higher $p \mathrm{H}$, produces more hydrogen sulphide on heating, with resultant staining of cans, and it was suggested that the addition of lactic acid to the meat before canning would reduce such staining. The effects of the removal of muscle from the bones and of proteolytic enzymes on tenderness were also investigated. A pea sheller developed by the Division gave higher recovery of peas than did commercial viners. The rate of damage was reduced, the quality of peas being comparable with that obtained by hand shelling.

\section{Palynological Society of India}

THE Palynological Society of India was founded by an internationally representative section of palynologists, and was inaugurated on January 5 at Calcutta, during the Combined 5I-52 Session of the Indian Science Congress. The Society has undertaken the publication of the Palynological Bulletin and the Journal of Palynology (both of which are annual publications). The membership of the Society is open to all scientists of all nationalities interested in the study of pollen and spores. There are two types of membership, namely: (1) Life Membership, and (2) Ordinary Membership (apart from Institution Membership), in each of which there are two categories $A$ and $B$. Institution members and members of category $A$ (Life/Ordinary) are entitled to free copies of both the Journal of Palynology and the Palynological Bulletin, while those in category $B$ (Life/Ordinary) are only entitled to the Palynological Bulletin. The membership foes are as follows: Life Membership, Category $(A)$. Rs. 100; 24 dollars; $£ 8$ (consolidated). Category $(B)$. Rs. $30 ; 8$ dollars; $£ 3$ (consolidated). Ordinary
Membership. Category $(A)$. Rs. 10;2.4 dollars; 14s. per annum. Category $(B)$. Rs. $3 ; 1$ dollar; $8 s$. per annum. Institution Membership, Rs. 15; 4 dollars; $£ 1$ per annum. Admission fee, Rs. 2; 48 cents; $3 s$. for all categories of membership. Further information and membership forms can be obtained from Dr. P. K. K. Nair, general secretarytreasurer, Palynological Society of India, National Botanic Gardens, Lucknow.

\section{Testing for Seed Health}

Provision of disease-free seed in agriculture and horticulture is an important factor in raising productivity of food crops. The International Seed Testing Association, Wageningen (Holland), is working towards the accumulation of sufficient knowledge to be able to specify methods for testing seed health which would command world-wide acceptance. A most timely and welcome contribution to this end, from the Plant Pathology Division, Ministry of Agriculture, The Queen's University, Belfast, has recently been published by the Association (Seed-Borne Fungi: Descriptions of 77 Fungus Species. Handbook of Seed Health Testing, Series 4 (1). By J. P. Malone and A. E. Muskett. Pp. ii +179-384. Wageningen: The International Seed Testing Association, 1964. 2.05 dollars). The essential feature of the Ulster method is the plating out of seeds on malt extract agar, with or without previous surface sterilization. It is then necessary to be able to distinguish the truly parasitic fungi from those causing little or no damage, so the Handbook gives sufficiently detailed descriptions of 77 species or species groups to provide almost forensic standards for recognition. There are, moreover, 284 excellent photomicrographs and photographs of cultures to assist in diagnosis, all of them the sort of practical views encountered in day-to-day examinations. It should be noted that an effective examination for seed contaminants should declare the greatest risk of disease from the sample, but this does not mean that such an amount will necessarily develop, for disease occurrence needs favourable conditions of environment and host reaction in addition to the presence of a parasite. The problem is complicated by the fact that certain seed contaminants may be symbionts beneficial to the plant (for example, an endophytic fungus on Lolium spp.) or they may diminish the activity of more active parasites (for example, Chaetomium spp. have been held responsible for the low incidence of disease caused by Helminthosporium victoriae on oats in Brazil). On the other hand, such potential food grain contaminants as Aspergillus fumigatus and Claviceps spp. are dangerous to man and livestock, and many fungi deteriorate seeds stored for food. It is therefore essential to be able to assess seed: contamination, or more positively seed health, and the detailed information in the Handbook should have ready and wide acceptance.

University News:

Liverpool

Dr. J. R. Anderson has been appointed to the George Holt chair of pathology. Dr. E. Parry has been appointed senior lecturer in anatomy. The following lecturers have also been appointed: Dr. M. J. Roberts (applied mathematics); A. H. Cookson (electrical engineering and electronies).

DR. P. G. MurpHy has been appointed to the newly established additional chair of physics. The following lecturers have been appointed : Dr. B. J. G. Johnson and Dr. E. Hutton (chemistry); Dr. F. M. Cole (pathology); N. E. Long and Dr. G. K. Garbett (social anthropology); Dr. R. A. James (astronomy); K. S. Williams (mathematics); R. W. Morgan and R. Morton (mathematical statistics); Dr. J. A. D. Ackroyd (mechanics of fluids); Dr. D. G. Lees (metallurgy); Dr. J. G. Baker and Dr. M. A. H. McCausland (physics); Dr. L. M. Cook (zoology); Dr. J. R. Rintoul (anatomy). 